NBER WORKING PAPER SERIES

\title{
THE RELATIONSHIPS BETWEEN MENTAL HEALTH AND SUBSTANCE ABUSE TREATMENT AND JUVENILE CRIME
}

\author{
Alison Evans Cuellar \\ Sara Markowitz \\ Anne M. Libby \\ Working Paper 9952 \\ http://www.nber.org/papers/w9952 \\ NATIONAL BUREAU OF ECONOMIC RESEARCH \\ 1050 Massachusetts Avenue \\ Cambridge, MA 02138 \\ September 2003
}

The views expressed herein are those of the authors and not necessarily those of the National Bureau of Economic Research.

(C2003 by Alison Evans, Sara Markowitz, and Anne M. Libby. All rights reserved. Short sections of text, not to exceed two paragraphs, may be quoted without explicit permission provided that full credit, including (C) notice, is given to the source. 
The Relationships between Mental Health and Substance Abuse Treatment and Juvenile Crime Alison Evans Cuellar, Sara Markowitz, and Anne M. Libby

NBER Working Paper No. 9952

September 2003

JEL No. I0, K4

\section{$\underline{\text { ABSTRACT }}$}

The purpose of this paper is to examine the effectiveness of mental health and substance abuse treatment in reducing crimes committed by juveniles. The observed high correlations between crime, substance abuse and poor mental health suggests that factors which reduce substance abuse and improve mental health may also be effective in reducing criminal activities. This paper uses detention data in conjunction with substance abuse and mental health treatment data for youth enrolled in the Colorado state foster care program. We analyze the impact of treatment in delaying or preventing this group of at-risk youth from engaging in criminal behavior. Results show a negative effect, i.e., longer duration before detention, for youth who receive treatment and for youth in areas with high treatment rates.

Alison Evans Cuellar

Department of Health Policy and Management

Columbia University

600 W. 168th Street, 6th Floor

New York, NY 10032

ac2068@columbia.edu

Sara Markowitz

Rutgers University, Newark and

NBER

365 Fifth Ave, 5th floor

New York, NY 10016

smarkow@newark.rutgers.edu

Anne M. Libby

Department of Psychiatry

University of Colorado Health Sciences Center

Denver, CO 80262

anne.libby@uchsc.edu 


\section{INTRODUCTION}

Criminal behaviors are highly prevalent among adolescents. In 2000, teenagers aged 13 to 19 accounted for 10 percent of the population, but 25.8 percent of all arrests, 23.8 percent of arrests for violent crime, and 40 percent of arrests for property crime (FBI, 2000). There is a large body of literature examining the determinants of juvenile crime, which concludes that factors such as gender, education, socio-economic status, and family environment are all strong correlates of criminal behavior. Two factors, substance abuse and mental illness, have received less attention in the crime literature, but are also potentially important. This paper examines the effectiveness of mental health and substance abuse treatment in reducing crimes committed by juveniles.

A number of studies have shown that youth with substance abuse or mental health disorders consistently have higher offending rates than those without disorders (Elliott and Huizinga, 1984; Elliott and Huizinga, 1989; Elliott et al.,1989; Elliott et al.,1986). For example, Vander Stoep et al. (1997) show that youth enrolled in a public mental health system had three times as many police referrals to the juvenile justice system as those in the general child population. Others have shown higher rates of violence and aggression among youth with mental health problems (Ellickson et al.,1997; Arseneault et al.,2000). Some evidence suggests that mental illness contributes in part to youths' illegal behavior (Loeber et al.,1998; Lynam, 1996; Loeber et al., 2000; Link and Stueve, 1995).

Similarly, a number of studies have shown that children in the juvenile justice system experience substantially higher rates of mental health and substance abuse disorders than youth in the general population (Garland et al.,2001; Randall et al.,1999; Myers et al.,1990; Wasserman et al., 2002; Friedman et al., 1996). For example, Wasserman et al. (2002) studied 
past-month mental health diagnoses among a group of male youth in secure placement facilities and found expectably high rates of disruptive diagnoses ( 33 percent), but also high rates of substance abuse diagnoses ( 50 percent), anxiety disorders (20 percent) and mood disorders (10 percent). By comparison, estimates for youth ages 18 and under from the nationally representative National Comorbidity Survey show a much lower past year prevalence of substance abuse disorders (11 percent), but similar rates of anxiety disorders ( 25 percent) and mood disorders (13 percent). The use of different instruments and survey time frames across studies makes comparisons difficult, but a review of impairment studies among general population youth reported the median rate of any disorder to be 15 percent (Roberts, et al., 1998).

Studies of substance abuse and crime, whether violent or nonviolent, show a strong positive relationship (see Miczek et al.,1994, and Forrest and Gordon, 1990 for reviews of the literature). Regarding violent crime, the Bureau of Justice Statistics (1998) states that a higher proportion of violent male inmates in local jails report drinking at the time of the offense than property crime inmates. Among all state prisoners under the influence of alcohol at the time of the offence (about $33 \%$ of prisoners), the average blood alcohol content (BAC) is 0.27 , which is almost 3 times that of the legal limit for driving under the influence. In comparison, the average BAC for intoxicated drivers involved in fatal accidents is about 0.17 (BJS 1998). Other studies comparing violent and non-violent criminals also find high rates of alcohol use among violent offenders (Roslund and Larson, 1979; Myers, 1982; Myers, 1986).

In considering violence by youths, Rossow et al. (1999) and Bernburg and Thorlindsson (1999) show that when violence is measured as a specific act, such as beating or threatening to beat someone or having been in a fight with a weapon, frequent intoxication will lead to increased violence, as will the use of marijuana or other drugs. Salts and Lindholm (1995) find 
that alcohol and marijuana use are highly correlated with increased violent behaviors in both black and white adolescent males. Similar findings hold for teens of both genders when examining drug use and violence in school (Furlong et al., 1997).

It is important to note that the studies showing the high correlation between mental illness, substance use, aggression, and crime do not establish causality. There could exist unobserved individual, familial, or situational confounders driving these relationships (see Fagan 1990 for a review of the theories on intoxication and aggression). However, if having a mental illness or substance abuse disorder causes crime, for example, due to aggression or lack of impulse control, then targeting the disorder through health care treatment may reduce the likelihood of subsequent offense and contact with the juvenile justice system. As a result, increased availability of mental health and substance use treatment programs may be an effective means by which to reduce crime. Among substance users, if consumption directly causes crime, then another way to lower crime would be to lower consumption. Indeed, a number of studies have shown that crime can be reduced by raising price of drugs or alcohol (Chaloupka and Saffer, 1992; Cook and Moore, 1993; Markowitz, 2000; DeSimone, 2001; Markowitz, 2001).

Using data on a group of at-risk teenagers in the Colorado child welfare system, we examine the effectiveness of mental health and substance abuse treatment in reducing juvenile crimes. This study also focuses on the effectiveness of increased access to treatment for substance abuse and mental illness and higher alcohol prices in reducing crime. As described in detail below, we focus on improved access to treatment and higher alcohol prices since policy makers can easily manipulate the demand for treatment and the demand for alcohol through policy changes, for example, through changes in public health insurance programs or higher excise taxes on alcohol. 
Using duration models to examine the determinants of the time spent out of detention, we find that mental health and substance abuse treatment reduce detention hazards for all offenses and violent offenses, as do higher prices for alcohol. The effect of alcohol prices is particularly strong among violent offenses. Increased availability of treatment services will also lower detention hazards for all offences, but appear to have no effect on violent offenses.

The paper is organized as follows: Section 2 describes the relevant literature. Section 3 addresses the data and methods used in the study, while Section 4 reports the results. We conclude with Section 5.

\section{RELEVANT LITERATURE}

There has been very little research examining the effectiveness of mental health treatment in preventing crime by youths, although one form of intensive treatment, multisystemic therapy (MST), has been shown to have beneficial effects and reduce rates of subsequent arrests, psychiatric symptomatology, and drug use for youth with serious antisocial behavior (Henggeler, 1994; Henggeler et al., 1996). The MST intervention provides highly coordinated and organized services whereby therapists involve parents, teachers, and friends to focus on environmental change. Although MST has been tested in randomized trials, thereby dealing with the problem of sample selection, these studies have been limited to small study populations with serious disorders in controlled environments. Broader effectiveness of less intensive mental health services on youth crime has not been established.

There are however, a number of studies focusing on substance abuse treatment in reducing crime, but this literature applies mostly to adults. There are a number of different kinds of treatment programs for substance abuse, although most evaluation studies have focused on 
four primary types: methadone maintenance, therapeutic communities, outpatient drug free programs, and civil commitment programs. Methadone maintenance programs provide methadone to drug-dependent individuals as an oral substitute for heroin. These types of programs seem to be successful in reducing both drug consumption and crime (Anglin and Hser, 1990). For example, Hser et al. (1988) show that for heroin addicts, time spent involved in property crimes decreased from 18 percent of the time when not in treatment to 11 percent during treatment. Hunt et al. (1984) compared clients at a methadone maintenance clinic with narcotic users who were not in treatment. They find that those in treatment are less involved in burglary, robbery and drug dealing. Maddux and Desmond (1979) find that crime rates in San Antonio, Texas decreased as methadone treatment rates increased, and that crime rates increased when budget cutbacks forced the premature discharge of patients.

Therapeutic communities are residential drug and alcohol treatment facilities designed with the goal of helping the individual maintain a drug-free lifestyle. Programs include encounter group therapy, and education sessions. In a study of one such community, DeLeon et al. (1979) tracked males who entered the Phoenix House program in 1970-1971, and found that the percent arrested fell from 72 prior to treatment to 41 after treatment. DeLeon (1984) shows similar reductions.

Outpatient drug-free programs, which provide counseling and training in social skills, seem to be less effective in reducing crime than other types of programs. Hubbard et al. (1984)report that the same proportion of clients engaged in illegal activities before and after treatment.

In a more general study that does not focus on a specific treatment, Saffer et al. (2001) look at the impact of state-level expenditures for drug treatment facilities on illicit drug 
consumption and finds that higher levels of expenditures are associated with reduced drug use. These expenditures include money spent on hospital facilities operated by state or local governments, and payments to private facilities. Saffer (2001) examine the impact of state-level expenditures for drug control activities on crime. Drug control activities include police, courts, prosecution, public defense, education, and drug treatment. He finds that states which spend more per capita on drug control activity have lower arrests, lower reported property damage and fewer individuals selling drugs.

Jofre-Bonet and Sindelar (2002) also examine the impact of unspecified types of drug treatment programs in reducing crimes. This study follows a sample of inner-city drug users through treatment for drug and alcohol addiction, and relates the changes in drug use to changes in income-generating crimes. They find that reductions in drug use are strongly related to reduction in crime, and suggest that treatment which lowers drug use may be an effective tool for reducing crime.

Finally, a number of researchers have examined the effectiveness of civil commitment programs. Typically, a drug addict will be ordered by the court to complete one of these programs as an alternative to prison. McGlothlin, et al. (1977) compared addicts who completed a court ordered program to those addicts who did not complete the court ordered program. Results show the former group reduced their criminal activity by 18.6 percent as compared to a 6.7 percent reduction by the latter group. Van Steel et al. (1994) look at recidivism to the criminal justice system for criminals who entered Wisconson's Treatment Alternative Program (TAP) over a one year period. They find that offenders who completed TAP were less likely to be rearrested during the follow-up period than offenders who did not complete TAP. Sealock et al. (1997) use data from offending youths assigned to substance abuse treatment in a resident 
facility in Maryland. Results show that youths in residential treatment facilities were no less likely to be arrested during the follow-up period than those not receiving treatment. However, the treatment youths remained arrest-free longer.

In short, substance abuse treatment programs appear to be effective in lowering crime. However, the existing literature tends to focus on limited samples of adults or restricted geographic areas. The studies primarily fall into two main types: those which look at rates of criminal behavior by substance abusing individuals before and after treatment, and those comparing a control group of criminals to a treatment group of criminals. One drawback to the first type of study design is that it is difficult to attribute behavioral changes to the program or the passage of time. Both types may also suffer from biases in sample selection, and the results may not be applicable to a larger youth population.

\section{Methods}

\subsection{Data}

The above literature review suggests an empirical model where crime is determined in part by drug and alcohol consumption and poor mental health. If treatment for substance abuse or mental health problems is successful, then such treatment may also reduce criminal activities. We test this hypothesis by estimating a model of crime for a group of at-risk teenagers who are in the Colorado child welfare system (i.e. foster care). We then test a separate model for violent crimes only. The child welfare population is an interesting and relevant population to study because the majority of the children in foster care programs across the country come from abusive or neglectful homes, and as a result, these children exhibit more chronic medical, emotional, and psychological problems than other youth (DosReis et al. 2001). These children 
are considered at-risk for criminal behaviors because of the link between mental health and substance abuse problems and crime as discussed above.

Our sample consists of youth in the child welfare system over a three-year period. The child welfare encounter data come from the Colorado Division of Child Welfare and contain records for all youth who received child welfare services in Colorado between July 1994 and June 1997. These data include date of entry, age, gender, race, ethnicity, and county of residence. Our sample consists of youth between the ages of 13 and 18 who were in the child welfare system or entered it during the study period.

Data on crime come from the Department of Youth Corrections (DYC), which collects information on all youths who are detained. Crime in this study is measured by youth who are arrested and specifically detained by the Colorado Division of Youth Corrections. Their cases are not necessarily adjudicated and may not lead to sanctions. Therefore, our measure of crime is more restrictive than arrests, but less restrictive than sanctioning or commitment. The DYC data contain date of detention and release, as well as offense type. A wide range of offenses is recorded in the system, including violent crimes, property crimes, drug crimes, sex crimes, minor crimes, and status offenses. We exclude detentions due to status offenses. For analyses of violent crime, we use detentions for murder, rape, assault, and robbery offenses. In our sample, 20.1 percent of youths are detained by the department of corrections at least once during the three-year sample period, and 3.2 percent are detained for violent offenses. When an individual was observed to have multiple detentions, only the initial spell up to the first detention was included in the analysis. Consequently, we do not address the issue of recidivism in this study.

Children in foster care are entitled to benefits under Medicaid, and these benefits include treatment for substance abuse and mental health problems. Medicaid claims and encounter data 
provide the information on mental health and substance abuse treatment for the teenagers in our sample. ${ }^{1}$ These data include dates of treatment service and treatment type. Treatment type includes outpatient treatment (including individual and group therapy, crisis and evaluative services, case management, day treatment programs) and services in therapeutic residential treatment facilities.

All datasets contain individual-level, encrypted identifiers. Teenagers in the child welfare system during the study period were matched to their Medicaid and detention records using the identifiers. The sample is composed of 6,073 youth. The mean characteristics of the sample are shown in Table I.

\subsection{Measures}

Dependent Variable. Our dependent variables are indicators for whether a youth was detained for any offense and whether a youth was detained for a violent offense only. Data for each individual are aggregated to monthly discrete observations. Consequently, the detention variable takes on a value of 1 if that individual was detained in the respective month and zero if not. Similarly, we aggregate detention for violent offenses by month. Individuals are assumed to occupy only two states, detention-free and detained. The transition rate from one state to the other is the probability of leaving the detention-free state at any time period, given that the individual is not detained up to that time period.

${ }^{1}$ Services that are reimbursed through the state's behavioral health managed care contracts are reported using "encounter data," while services reimbursed under fee-for-service contracts are reported using claims. The Medicaid encounter and claims data were analyzed over a year after the state submission deadline, allowing time for delayed records to be processed. 
Key Independent Variables. The provision of mental health and substance abuse treatment is our primary explanatory variable of interest. Treatment is defined as equal to one if the individual was treated in a given month and zero otherwise. Treatment includes outpatient treatment or treatment in a therapeutic residential treatment facility. Any youth hospitalized as an inpatient (in acute, general and psychiatric hospitals or state mental hospitals) is considered censored at the time of admission as they are not at risk of being detained while in the hospital. None of the treatment visits recorded in this data results from a court-ordered sentence.

Estimating this model will show the propensity of treatment to reduce crime, although a problem will arise if the decision to receive mental health or substance abuse treatment is influenced by the same individual characteristics as the decision to commit a crime. In this case, treatment will be endogenous and its coefficient will be biased. In order to correct for this potential endogeneity, we use an estimation strategy which accounts for unobserved individual heterogeneity (described below).

A second method of avoiding the problems associated with the endogeneity of treatment is to estimate a model of crime that substitutes for treatment those variables that are correlated with treatment, but not crime directly. This is in the same spirit as the crime and substance use papers by Cook and Moore (1993) and DeSimone (2001) that relate the prices of drugs and alcohol directly to crime. In our case, ideally the price of treatment would serve as such a variable given that a number of studies have shown that the demand for mental health and substance abuse services is responsive to price (Frank and McGuire 2000). However, since all children in foster care are eligible for Medicaid, the monetary price of treatment faced by each individual is zero and does not vary. Instead, we use a measure of the full price of treatment, which includes travel and waiting times. This can be represented by county-level treatment 
rates, calculated as the proportion of the sample treated in the given month, that capture the supply of treatment available. We expect that as county treatment rates rise, the full price of treatment falls. ${ }^{2}$

In a model where crime is determined in part by alcohol consumption, treatment may not be the only determinant of alcohol consumption. A number of studies have shown that the consumption of alcohol varies with its price (Leung and Phelps, 1993; Cook and Moore, 2000). We include the price of beer in all models to gauge the effectiveness of higher beer prices in reducing crime, holding treatment constant. Beer prices are available for a number of different cities across Colorado. These data are published quarterly from the American Chamber of Commerce Research Association. Each individual in the sample is assigned a beer price based on the county of residence.

Control Variables. Explanatory variables that do not change over time include demographic variables. Age by category (age 13 to 14 , age 15 to 16 , and 17 or older) is defined as the age when the individual is first observed, that is, at entry into the child welfare system. We also control for race (whether the individual is white, black, with other races as the omitted category) and for whether the individual is Hispanic or not.

\subsection{Estimation Strategy}

Duration models are used to examine the structural determinants of detention. These models analyze the decision to make a transition from one discrete state to another. We estimate

\footnotetext{
${ }^{2}$ Treatment rates are calculated based on the entire sample of youth, not just those detained by the department of Youth Corrections. The county rate serves as a valid measure of availability of services since it is unlikely that any one individual's behavior will influence the county treatment rate.
} 
the conditional probability that an individual observed in the first period (month) will be detained in a subsequent period (month). In particular, we estimate the extent to which characteristics of the individual, alcohol prices, and treatment affect the length of time spent detention-free. Therefore, these methods will quantify the impact of changes in the determinants of detention on the conditional probability of being detained. The starting hazard rate is the probability of being detained in period $t$, conditional on not being detained prior to $t$. The starting hazard should rise and fall over time in response to different stimuli. In particular, the results will show how changes in prices of alcohol and the provision of treatment affect length of time an individual remains detention-free.

We model duration using several specifications. The unit of analysis is a spell, which may be right-censored. Right-censoring occurs if we do not observe an individual being detained during the study period, if the youth is treated as an inpatient in a hospital, or turns 18. Within each spell we observe from 1 to 36 spell months. Conditional exit probabilities in each spell month depend on observed fixed and time-varying covariates. We use maximum likelihood estimation whereby the log likelihood is given by Eq. (1):

$$
\log L=\sum_{i=1}^{n}\left\{y_{i} \log h\left(X_{i}\right)+\left(1-y_{i}\right) \log \left[1-H\left(X_{i}\right)\right]\right\},
$$

where $y_{i t}$ is an indicator variable equal to one if person $i$ exits the state during the interval $[t-1, t]$, $h($.) is the density function and $H($.$) is the cumulative distribution function. The first term is the$ contribution of an individual who is detained during the study period and the second term is the contribution of an individual who is not detained. 
We use a semi-parametric estimation procedure, the complementary log-log specification of Prentice and Gloeckler (1978). ${ }^{3}$ This is a semi-parametric model, where we estimate a fully non-parametric baseline hazard with a separate parameter for each duration interval. That is, we assume the form of the baseline hazard is a step function with a step at each interval. Unlike a parametric approach, such as a Weibull specification, in this method it is unnecessary to make parametric assumptions concerning the hazard's time dependency that can lead to inconsistent coefficient estimates if the parameterization fits the data badly.

In addition, we estimate a model that incorporates unmeasured heterogeneity, also called frailty. Unmeasured heterogeneity leads to overstated duration dependence (i.e., underestimates of the extent to which the hazard rate increases with duration) and attenuates the magnitude of the impact of covariates on the hazard rate (Lancaster, 1990; Kiefer, 1988). Without accounting for unobserved heterogeneity, the results may be biased. We incorporate a gamma mixing distribution to capture unobserved heterogeneity as proposed by Meyer (1990).

\section{RESULTS}

Table II presents the effect of treatment, beer prices and other covariates on the duration hazard. The result table shows exponentiated coefficients or hazard ratios. Values greater than one indicate that the covariate increases the exit probability (increase the likelihood of being detained) while values less than one decrease the exit probability. Column 1 shows that black youth have significantly higher probabilities of exiting into detention (i.e., their detention-free spells are shorter) than other races, as do Hispanic youth and youth who are older. In addition, males have higher exit probabilities than females. The demographic patterns are consistent with evidence from FBI arrest data (Snyder, 1998). The key policy variables in this analysis also

\footnotetext{
${ }^{3}$ It is implemented using pgmhaz command in Stata (Version 7).
} 
behave as predicted. Youth who receive mental health or substance abuse treatment have significantly lower probabilities of exiting into detention (i.e., their spells are longer). Receiving treatment is associated with a 72 percent decline in the detention hazard. Beer prices also have significant, negative effects on exit into detention, lowering the hazard by 42 percent for every dollar increase in the beer price. Note that a dollar increase in the price of a six-pack of beer represents a 24 percent increase in the average price.

Column 2 uses county treatment rates, the proxy for price of treatment, rather than individual treatment. Coefficients on the demographic variables are similar to Column 1 . The hazard rate is less than one and is statistically significant. This implies that youth in counties with higher treatment rates have lower conditional exit probabilities consistent with the theoretical model's prediction that increased availability of treatment improves access and lowers crime. The coefficient on beer prices remains statistically significant and implies a lower probability of exit (a longer period detention free).

Columns 3 and 4 of Table II present estimates from models that incorporate unmeasured heterogeneity. We compare the models with and without heterogeneity terms by testing the significance of the variance parameter in the gamma distribution and by the likelihood ratio test. We find that introducing the heterogeneity terms improves the model fit. The estimated Gamma variance has a t-value of 5.17 (p-value $<0.01$ ) and 4.53 (p-value $<0.01$ ) in each model, while the likelihood ratio statistic for testing the models is $38.05\left(\chi^{2}<0.01\right)$ and 28.01 respectively $\left(\chi^{2}<0.01\right)$.

The magnitude of the effect of individual treatment is slightly greater in the model with heterogeneity. Having received treatment lowers the hazard by 75 percent. Omitting the heterogeneity terms leads to attenuation of the treatment effect. The demographic patterns are 
similar in the two models. Results that including unobserved heterogeneity show that males and youth of older ages have higher detention exit rates. In both models, beer prices reduce the detention hazard.

Similarly, in column 4 , when accounting for unobserved heterogeneity, treatment rates and beer prices both are statistically significant and lower the probability of exit into detention. In all four of the above models, the coefficients on the duration dummy variables (not shown) indicate that the pattern of variation of the baseline hazard with duration is not monotonic.

The effect of covariates on the hazard of detention for a violent offense are reported in Table III. We find that receipt of treatment has statistically significant attenuating effect on detention hazards (column 1), while beer prices have a larger effect than in previous models. Treatment is associated with a 75 percent decline in the hazard, while a dollar increase in beer prices is associated with an 82 percent decline. In contrast to previous models, in models of violent offenses only, the effect of treatment rates is no longer significant (column 2). The effect of beer prices remains statistically significant in column 2 .

As for all offences, we find that introducing the heterogeneity term improves the model fit of violent offences. The estimated Gamma variance has a t-value of 2.83 (p-value <0.01) and 2.45 (p-value $<0.01$ ) in each model, while the likelihood ratio statistic for testing the models is $13.04\left(\chi^{2}<0.01\right)$ and 9.07 respectively $\left(\chi^{2}<0.01\right)$. Models of detention for violent offenses that incorporate unmeasured heterogeneity also show negative effects of mental health and substance treatment and beer prices on the detention hazard for violent offenses (column 3). In contrast to models of all offense types models, the effect of county treatment rates is not significant for violent offenses, although the effect of beer prices remains negative and significant (column 4). 


\section{SUMMARY AND CONCLUSIONS}

This study examines the effectiveness of mental health and substance abuse treatment in reducing detention rates for juveniles in the Colorado child welfare system. This is a important group of youth to study since they are particularly at risk for engaging in criminal behaviors. The majority of the children in foster care programs across the country come from abusive homes and as a result, these children exhibit more chronic medical, emotional, and psychological problems than other youth. Indeed, our analysis shows high detention rates among this group. Consistent with other youth studies we also find that among youth in child welfare those who are male, black, Hispanic and older were likely to be detained earlier than other youth.

Using duration analyses, we find that substance abuse and mental health treatment can be used effectively to delay or prevent youth detention. Specifically, the analysis finds that individuals who receive treatment have lower probabilities of being detained for any offence. Similarly, those youth who live in areas with a greater supply of treatment services also have a lower probability of exiting into detention. Accounting for the unobserved heterogeneity makes the magnitude of these effects larger. Also consistent with our theory, higher beer prices lower the detention hazard.

In examining the determinants of detention for violent offences, we show that individuals who receive treatment have lower probabilities of being detained, however, the supply of treatment in the area does not impact the length of time out of detention. The effect of higher beer prices is negative and particularly strong. Given the often cited high correlation between alcohol use and aggression, this last result is not surprising and implies that higher beer prices will reduce both consumption and violent criminal behaviors. 
The results of out study are limited by the fact that we can not identify the effectiveness of specific mental health or substance abuse treatment components. In addition, the analysis is conducted on a specialized sample of foster care youth in Colorado and results may not be generalizable. However, this group has a high rate of criminal involvement and may be relatively easy to target for public policies because they are already in a public system. Results of this study suggest that expansion of health services targeted at these youth may be effective at reducing crime. For violent crime, where the literature shows that substance abuse plays a significant role, stricter alcohol-regulatory policies may also be highly effective. 


\section{References}

Anglin, M.D. and Hser, Y. (1990). Treatment of drug abuse. In Tonry, M., and Wilson, J.Q. (eds). Drugs and Crime, The University of Chicago Press, Chicago, pp 393-460

Bureau of Justice Statistics, U.S. Department of Justice. (1988). Report to the Nation on Crime and Justice. Second Edition. NCJ-105506.

Chaiken, J.M. and Chaiken, M. R. (1982). Varieties of Criminal Behavior: Summary and Policy Implications. Rand, Santa Monica, CA.

Chaloupka, F.J., and Saffer, H. (1992). Alcohol, illegal drugs, public policy and crime. Presented at the annual meeting of the Western Economic Association, San Francisco, CA.

Cook, P.J., and Moore, M.J. (1993). Economic perspectives on reducing alcohol-related violence. In Martin, S. E. (ed.), Alcohol and Interpersonal Violence: Fostering Multidisciplinary Perspectives National Institute on Alcohol Abuse and Alcoholism Research Monograph 24. NIH Publication No. 93-3469.U.S. Government Printing Office, Washington, DC.

Cook, P.J. and Moore, M.J. (2000) Alcohol. In Culyer, AJ and Newhouse, J.P. Handbook of Health Economics Vol 1B. North-Holland, New York, 1629-1673.

DeLeon, G. (1984). Program-based evaluation research in therapeutic communities. In Tims, F.M. and Ludford, J.P.(eds.), Drug Abuse Treatment Evaluation: Strategies, Progress and Prosepects, National Institute on Drug Abuse Research Monograph no. 51. U.S. Department of Health and Human Services, National Institute on Drug Abuse, Rockville, MD. 
DeLeon, G. AndrewS, M.P.A., Wexler, H.K. Jaffe, J. and Rosenthal, M.X. (1979). Therapeutic community dropouts: criminal behavior five years after treatment. American Journal of Drug and Alcohol Abuse, 6:253-71

DeSimone, J. (2001). The effect of cocaine prices on crime. Economic Inquiry, 39:4.

DosReis, S., Zito, J.M., Safer, D.J., Soeken, K.L. (2001) Mental health services for youths in foster care and disabled youths, American Journal of Public Health, 91(7): 1094-1099

Fagan, J. (1990). Intoxication and aggression, in Tonry M and Wilson JQ, (eds), Drugs and Crime, University of Chicago Press, Chicago

Fagan, J. (1993). Interactions among drugs, alcohol and violence. Health Affairs, 12:4, 65-79. Forrest, G. G., and Gordon, R. H. (1990). Substance Abuse, Homicide, and Violent Behavior. Garden Press, New York.

Frank, R.G. and McGuire, T.G. (2000). Economics and mental health. In Culyer, A.J. and Newhouse, J.P. (eds.), Handbook of Health Economics, Vol. 1B. Elsevier, Amsterdam.

Goldstrom, I, Jaiquan, F. Henderson, M. Male, A., Manderscheid, R. W. (2000) The availability of mental health services to young people in juvenile hustice facilities: A national survey. In Manderscheid, R. W. and Sonnerschein, M. A. (eds.), Mental Health, United States, 2000 . U.S. Department of Health and Human Services, Substance Abuse and Mental Health Services Administration, Center for Mental Health Services, Washington, DC Garland, A.E., Hough, R.L., McCabe, K.M., Yeh, M., Aarons, G.A. (2001). Prevalence of psychiatric disorders in youths across five sectors of care. Journal of the American Academy of Child Adolescent Psychiatry, 40(4):409-417

Goldstein, P.J. (1985). The drugs/violence nexus: a tripartite conceptual framework. Journal of Drug Issues. 15: 493-506. 
Henggeler, S.W. (1994). A consensus. Conclusions of the APA Task Force report on innovative modesl fo mental health services for children, adolescents, and their families. Journal of Clinical Child Psychology 23(Supl): 3-6.

Henggeler, S. W., Cunningham, P.B. Picrel, S.G., Scheonwald, S.K., Brondino, M.J. (1996). Multisystemic Therapy: An effective violence prevention approach for serious juvenile offenders. Journal of Adolescence 1: 47-61

Hser, Y., Anglin, M.D. and Chou, C. (1988). Evaluation of drug abuse treatment: A repeated measure design assessing methadone maintenance. Evaluation Review, 12(5): 547-70

Hubbard, R.L., Rachal, J.V., Craddock, S.G. and Cavanaugh, E.R. (1984). Treatment outcome prospective study (TOPS): client characteristics and behaviors before, during and after treatment." In Tims, F.M. and Ludford, J.P. (eds.) Drug Abuse Treatment Evaluation: Strategies, Progress and Prosepects, National Institute on Drug Abuse Research Monograph no. 51. U.S. Department of Health and Human Services, National Institute on Drug Abuse, Washington, DC.

Hunt, D.E., Lipton, D.S. and Spunt, B. (1984). Patterns of criminal activity among methadone clients and current narcotics users not in treatment. Journal of Drug Issues, 14(4): 687702.

Jenkins, S. P. (1995) "Easy estimation methods for discrete-time duration models.” Oxford Bulletin of Economics and Statistics 57(1): 129-138.

Jenkins, S. P. (1997) Estimation of discrete time (grouped duration data) proportional hazards models: pgmhaz," Stata Technical Bulletin Reprints, STB 17, 7: 109-121

Jofre-Bonet M. and Sindelar, J.L. (2002). Drug Treatment as a Crime Fighting Tool. NBER Working paper \# 9038, July. 
Kessler, R., Crum, R., Warner, L., Nelson, C., Schulenberg, J. and Anthony, J. (1996). The lifetime co-occurrence of DSM-III-R alcohol abuse and dependence with other psychiatric disorders in the national comorbidity survey. Archives of General Psychiatry, 45: $313-321$.

Kiefer, N.M. (1988). Economic duration data and hazard functions, Journal of Economic Literature 26:646-679

Lancaster, T. (1990). The econometric analysis of transition data, Econometric Society Monograph No. 17, Cambridge University Press, Cambridge

Leshner, A. (2001). Drug abuse and mental disorders: comorbidity is reality. NIDA Notes, 14:4. Leung, S. F. and Phelps, C.E. (1993) 'My kingdom for a drink..?' A review of the price sensitivity of demand for alcoholic beverages. In Bloss, G and Hilton, M., Economic and Socioeconomic Issues in the Prevention of Alcohol-Related Problems. U.S. Government Printing Office, Washington, DC

Maddux, J.F. and Desmond, D.P. (1979). Crime and drug use behavior: an area analysis. Criminology, 19: 281-302

Markowitz, S. (2000). An economic analysis of alcohol, drugs, and violent crime in the national crime victimization survey. NBER working paper No. 7982

Markowitz, S. (2001). Criminal violence and alcoholic beverage control: evidence from an international study. In Grossman, M. and Hsieh, C.-R., The Economic Analysis Of Substance Use And Abuse: The Experience of Developed Countries and Lessons for Developing Countries, Edward Elgar Limited, United Kingdom.

McGlothlin, W.H., Anglin, M.D. and Wilson. B.D. (1977). An Evaluation of the California Civil Addict Program. National Institute on Drug Abuse, Rockville, MD. 
Meyer, B. D. (1990). Unemployment insurance and unemployment spells. Econometrica 58(4): $757-782$

Myers, W.C., Burket, R.C., Lyles, W.B., Stone, L., Kemph, J.P. (1990). “DSM-III diagnoses and offenses in committed female juvenile delinquents. Bulletin of the American Academy of Psychiatry and the Law. 18: 47-54.

Miczek, K.A., J.F. DeBold, M. Haney, J. Tidey, J. Vivian, and E.M. Weerts. (1994) Alcohol, drugs of abuse, aggression, and violence. in Reiss, A.J. and Roth, J.A. (eds.), Understanding and Preventing Violence, Volume 3. National Academy Press, Washington, D.C.

Myers, T. (1982). Alcohol and violent crime re-examined: self-reports from two sub-groups of scottish male prisoners. British Journal of Addiction. 77:399-413.

Myers, T. (1986). An analysis of context and alcohol consumption in a group of criminal events. Alcohol and Alcoholism. 21:, 389-395.

Pernanen, K. (1981). Theoretical aspects of the relationship between alcohol use and crime. In Collins, J.J. (ed.), Drinking and Crime: Perspectives on the Relationships between Alcohol Consumption and Criminal Behavior, The Guilford Press, New York.

Prentice, R. and Gloeckler, L. (1978) Regression analysis of grouped survival data with application to breast cancer data. Biometrics 34: 57-67

Randall, J., Hengeller, S.W., Pickrel, S.G., Brondino, M.J. (1999). Psychiatric comorbidity and the 16-month trajectory of substance-abusing and substance-dependent juvenile offenders, Journal of the American Academy of Child and Adolescent Psychiatry, $38: 1118-1124$ 
Roberts, R.E., Attkisson, C. and Rosenblatt, A. (1998) Prevalence of psychopathology among children and adolescents. Am J Psychaitry 144:715-725

Roslund, B. and Larson, C.A. (1979). Crimes of violence and alcohol abuse in sweden. International Journal of the Addictions, 14: 1103-1115.

Rossow, L., Pape H and Wichstrom, L. Young, Wet and Wild? Associations Between Alcohol Intoxication and Violent Behavior in Adolescence. Addiction, July 1999, 1017-31.

Saffer, H. (2001). Substance abuse control and crime: evidence from the national household survey of drug abuse. In Grossman, M. and Hsieh, C.-R. (eds.), The Economic Analysis Of Substance Use And Abuse: The Experience of Developed Countries and Lessons for Developing Countries, Edward Elgar Limited, United Kingdom

Saffer, H., Chaloupka, F.J. and Dave, D. (2001). State drug control spending and illicit drug participation. Contemporary Economic Policy, 19(2):150-161.

Sealock, M.D., Gottfredson, D.C. and Gallagher, C.A. (1997). Drug treatment for juvenile offenders: some good and bad news. Journal of Research in Crime \& Delinquency, 34(2): $210-237$

Snyder, H.N. (1998). Juvenile Arrests, 1997. Office of Justice Programs, Office of Juvenile Justice and Delinquency Prevention, Washington, DC

Van Stelle, K.R., Mauser, E. and Moberg, D.P. (1994). Recidivism to the criminal justice system of substance-abusing offenders diverted into treatment. Crime \& Delinquency, 40(2): $175-197$

Wasserman, G.A., McReynolds, L.S., Lucas, C.P., Fisher, P., Santos, L., (2002). The voice DISC-IV with incarcerated male youths: prevalence of disorder. Journal of the American Academy of Child and Adolescent Psychiatry. 41:314-321 
Table I: Mean Values, first spell

\begin{tabular}{lc}
\hline & Mean \\
& (Standard Deviation) \\
\hline Received Treatment & $15.1 \%$ \\
Mean Treatment Rate & $16.3 \%$ \\
& $(0.5)$ \\
Avg. County Beer Price & 4.23 \\
& $(.21)$ \\
Age 13 to 14 (omitted group) & $60.7 \%$ \\
Age 15 to 16 & $34.5 \%$ \\
Age 17 and up & $4.8 \%$ \\
Male & $49.0 \%$ \\
Female (omitted group) & $51.0 \%$ \\
White & $77.5 \%$ \\
Black & $11.9 \%$ \\
Other Race (omitted group) & $10.6 \%$ \\
Hispanic & $28.2 \%$ \\
Non-Hispanic (omitted group) & $70.8 \%$ \\
N & 6,073 \\
\hline
\end{tabular}


Table II: Proportional Hazard Model of Detention using all Offense Types

\begin{tabular}{|c|c|c|c|c|}
\hline & \multicolumn{2}{|c|}{ No Heterogeneity } & \multicolumn{2}{|c|}{ Gamma Heterogeneity } \\
\hline & $(1)$ & $(2)$ & $(3)$ & $(4)$ \\
\hline Treatment & $\begin{array}{c}0.28 \\
(0.21-0.37)^{* *}\end{array}$ & & $\begin{array}{c}0.25 \\
(0.19-0.33)^{* *}\end{array}$ & \\
\hline Treatment Rate & & $\begin{array}{c}0.04 \\
(0.00-0.33)^{* *}\end{array}$ & & $\begin{array}{c}0.04 \\
(0.04-0.36)^{* *}\end{array}$ \\
\hline Average County Beer Price & $\begin{array}{c}0.58 \\
(0.43-0.79)^{* *}\end{array}$ & $\begin{array}{c}0.63 \\
(0.46-0.85)^{* *}\end{array}$ & $\begin{array}{c}0.60 \\
(0.43-0.84)^{* *}\end{array}$ & $\begin{array}{c}0.64 \\
(0.46-0.88)^{* *}\end{array}$ \\
\hline White & $\begin{array}{c}0.69 \\
(0.57-0.84)^{* *}\end{array}$ & $\begin{array}{c}0.68 \\
(0.56-0.83)^{* *}\end{array}$ & $\begin{array}{c}0.66 \\
(0.52-0.84)^{* *}\end{array}$ & $\begin{array}{c}0.65 \\
(0.52-0.82)^{* *}\end{array}$ \\
\hline Black & $\begin{array}{c}1.26 \\
(1.01-1.57)^{*}\end{array}$ & $\begin{array}{c}1.25 \\
(1.01-1.56)^{*}\end{array}$ & $\begin{array}{c}1.41 \\
(1.07-1.86)^{*}\end{array}$ & $\begin{array}{c}1.36 \\
(1.05-1.78)^{*}\end{array}$ \\
\hline Hispanic & $\begin{array}{c}1.67 \\
(1.79-1.57)^{* *}\end{array}$ & $\begin{array}{c}1.70 \\
(1.49-1.95)^{* *}\end{array}$ & $\begin{array}{c}1.80 \\
(1.53-2.12)^{* *}\end{array}$ & $\begin{array}{c}1.82 \\
(1.55-2.14)^{* *}\end{array}$ \\
\hline Male & $\begin{array}{c}2.74 \\
(2.43-3.09)^{* *}\end{array}$ & $\begin{array}{c}2.64 \\
(2.34-2.98)^{* *}\end{array}$ & $\begin{array}{c}3.22 \\
(2.77-3.74)^{* *}\end{array}$ & $\begin{array}{c}3.03 \\
(2.61-3.51)^{* *}\end{array}$ \\
\hline Age 15 to 16 & $\begin{array}{c}1.25 \\
(1.11-1.41)^{* *}\end{array}$ & $\begin{array}{c}1.26 \\
(1.12-1.42)^{* *}\end{array}$ & $\begin{array}{c}1.24 \\
(1.07-1.43)^{* *}\end{array}$ & $\begin{array}{c}1.26 \\
(1.09-1.45)^{* *}\end{array}$ \\
\hline Age 17 and up & $\begin{array}{c}1.50 \\
(1.07-1.41)^{*}\end{array}$ & $\begin{array}{c}1.54 \\
(1.11-2.17)^{*}\end{array}$ & $\begin{array}{c}1.33 \\
(0.91-1.96)\end{array}$ & $\begin{array}{c}1.38 \\
(0.95-2.01)\end{array}$ \\
\hline Number of records & 81,689 & 81,689 & 81,689 & 81,689 \\
\hline Number of subjects & 6,073 & 6,073 & 6,073 & 6,073 \\
\hline Log likelihood & $-5,974$ & $-6,033$ & $-5,955$ & $-6,019$ \\
\hline Gamma variance & & & 1.31 & 1.12 \\
\hline Std error of gamma variance & & & $(0.25)^{* *}$ & $(0.25)^{* *}$ \\
\hline
\end{tabular}

$95 \%$ confidence intervals in parenthesis

*Significant at $\mathrm{p}>.05$ level **Significant at $\mathrm{p}>.01$ level

Coefficients on time dummies not shown 
Table III: Proportional Hazard Model of Detention using Violent Offenses Only

\begin{tabular}{|c|c|c|c|c|}
\hline & \multicolumn{2}{|c|}{ No Heterogeneity } & \multicolumn{2}{|c|}{ Gamma Heterogeneity } \\
\hline & $(1)$ & $(2)$ & $(3)$ & $(4)$ \\
\hline Treatment & $\begin{array}{c}0.25 \\
(0.12-0.50)^{* *}\end{array}$ & & $\begin{array}{c}0.20 \\
(0.09-0.42)^{* *}\end{array}$ & \\
\hline Treatment Rate & & $\begin{array}{c}0.40 \\
(0.00-118.80)\end{array}$ & & $\begin{array}{c}0.24 \\
(0.00-97.76)\end{array}$ \\
\hline Average County Beer Price & $\begin{array}{c}0.18 \\
(0.08-0.40)^{* *}\end{array}$ & $\begin{array}{c}0.18 \\
(0.08-0.41)^{* *}\end{array}$ & $\begin{array}{c}0.18 \\
(0.07-0.45)^{* *}\end{array}$ & $\begin{array}{c}0.18 \\
(0.07-0.45)^{* *}\end{array}$ \\
\hline White & $\begin{array}{c}0.79 \\
(0.48-1.30)\end{array}$ & $\begin{array}{c}0.77 \\
(0.47-1.28)\end{array}$ & $\begin{array}{c}0.74 \\
(0.39-1.40)\end{array}$ & $\begin{array}{c}0.72 \\
(0.38-1.33)\end{array}$ \\
\hline Black & $\begin{array}{c}1.67 \\
(0.98-2.82)\end{array}$ & $\begin{array}{c}1.65 \\
(0.98-2.79)\end{array}$ & $\begin{array}{c}2.06 \\
(1.01-4.21)^{*}\end{array}$ & $\begin{array}{c}1.98 \\
(0.99-3.94)\end{array}$ \\
\hline Hispanic & $\begin{array}{c}1.48 \\
(1.05-2.08)^{*}\end{array}$ & $\begin{array}{c}1.51 \\
(1.07-2.13)^{*}\end{array}$ & $\begin{array}{c}1.54 \\
(0.99-2.40)\end{array}$ & $\begin{array}{c}1.57 \\
(1.02-2.41)^{*}\end{array}$ \\
\hline Male & $\begin{array}{c}2.36 \\
(1.76-3.18)^{* *}\end{array}$ & $\begin{array}{c}2.26 \\
(1.68-3.04)^{* *}\end{array}$ & $\begin{array}{c}2.97 \\
(2.00-4.40)^{* *}\end{array}$ & $\begin{array}{c}2.70 \\
(1.85-3.95)^{* *}\end{array}$ \\
\hline Age 15 to 16 & $\begin{array}{c}1.43 \\
(1.07-1.91)^{*}\end{array}$ & $\begin{array}{c}1.45 \\
(1.09-1.93)^{*}\end{array}$ & $\begin{array}{c}1.29 \\
(0.88-1.90)\end{array}$ & $\begin{array}{c}1.36 \\
(0.94-1.97)\end{array}$ \\
\hline Age 17 and up & $\begin{array}{c}2.39 \\
(1.21-4.73)^{*}\end{array}$ & $\begin{array}{c}2.46 \\
(1.25-4.87)^{* *}\end{array}$ & $\begin{array}{c}2.39 \\
(1.01-5.67)^{*}\end{array}$ & $\begin{array}{c}2.44 \\
(1.06-5.63)^{*}\end{array}$ \\
\hline $\begin{array}{l}\text { Number of records } \\
\text { Number of subjects } \\
\text { Log likelihood } \\
\text { Gamma variance } \\
\text { Std error of gamma variance }\end{array}$ & $\begin{array}{l}92,261 \\
6,073 \\
-1,354\end{array}$ & $\begin{array}{l}92,261 \\
6,073 \\
-1,366\end{array}$ & $\begin{array}{l}92,261 \\
6,073 \\
-1,348 \\
12.88 \\
(4.56)^{* *}\end{array}$ & $\begin{array}{l}92,261 \\
6,073 \\
-1,361 \\
10.92 \\
(4.44)^{* *}\end{array}$ \\
\hline
\end{tabular}

$95 \%$ confidence intervals in parenthesis

*Significant at $\mathrm{p}>.05$ level $* *$ Significant at $\mathrm{p}>.01$ level

Coefficients on time dummies not shown 